results can be obtained than those derived from a judicious change of climate; and yet the invalid should be made to understand that no climate either in the United States or Europe possesses all the physical qualities that could be desired. The winter and spring climate of Aiken, though greatly superior to that of our Northern cities, is by no means perfect, and the invalid, while seeking to avail himself of the health-giving influences afforded by the special advantages there offered, must at the same time be constantly on guard to eschew its disadvantages. Of the various sources of danger, the most prominent is that arising from exposure during one of the sudden transitions from heat to cold, which are not unfrequently encountered, It may not be superfluous, moreover, to warn the physician that diseases in all stages are not amenable to a change of climate. The serious error is too often made of sending away patients suffering from advanced organic disease attended, perhaps, with extreme physical weakness, and in no condition to sustain the fatigne inseparable from a long journey. In such cases an acute fever is produced by the inevitable exposure incident to traveling, and possibly some new inflammatory affection is developed, all of which more than neutralizes any benefit that could be derived from a residence in even the most appropriate climate.

Of Aiken it may be said, in conclusion, that its tonic, bracing climate differs in no essential particular from that of the health resorts of the Northern Mediterranean. The locality cannot fail in the future to enjoy a hygienic preëminence, for, while it indeed offers fewer sources of attraction than the foreign sanitaria, it is, on the other hand, much more accessible, and the comparatively low price at which a season can be spent there places its remedial advantages within the means of many whose moderate circumstances would preclude the idea of a foreign trip.

\title{
A CASE OF HYDROPHOBIA.
}

BX C. M. JONES, M. D.

Mrs. L. W. was a healthy woman of thirty-five. She had complained at times of palpitation, and had had occasional hysterical attacks, sometimes violent. On the 31 st of last July, a black and tan terrier belonging to her had been irritated by children until he finally bit one of them. She was whipping him for this offense, when he seized the second finger of the right hand so tightly that force was required to break his hold. He was turned into the street, and two other children were bitten before he was killed. He was not at any time supposed to be mad. Two of the four had their wounds cauterized immediately. Mrs. W. and the remaining one, who was bitten in the face, had nothing done. Subsequently she appeared cheerful, though her mother thinks 
that she was really nervous and apprehensive. She continued well till September 28th, when she complained of headache, which was of short duration ; September 29th, she had intermitting chilly sensations, and a pain, rheumatic in character, most severe in the region of the right shoulder, whence it extended down the arm to the hand, and down the right thorax, not following the lines of any particular nerves. There was also pain in the region of the heart, for which a sinapism was applied. September $30 \mathrm{th}$, the pain was less severe, and before night had entirely disappeared; she became, however, uneasy and nervous. She began to draw two or three quick, panting respirations at intervals. She took only some light food, towards night had some aversion to taking liquids, and was so much worried that she sought medical advice.

I was first called in the forenoon of October 1st. The patient was in bed, nervous, restless, much depressed, alternately sitting up and lying down, or turning from one side to the other. She was free from pain, complaining of palpitation. No nausea nor vomiting. Menstruating since yesterday. Bowels constipated. Every few minutes she drew the quick inspirations said to have begun yesterday, caused apparently by spasmodic action of the diaphragm. The breathing in the intervals was natural. When offered a spoonful of milk she took the spoon with averted face, hesitated a moment, carried it suddenly to her mouth, swallowed hurriedly, and threw the spoon from her. Generally, but not invariably, the spasmodic respirations followed the effort. There was nothing noticeable about the cicatrix. Face gloomy, not flushed. The temperature was normal to the touch. Tongue clean. Nothing unusual in throat. Pulse 75 , natural. Nothing alnormal in lungs or heart. Bromide of potassium was ordered in frequent doses, and a laxative pill.

At six and ten P. M., her condition was essentially unchanged, though she expressed herself as feeling easier. She had taken the medicine regularly without difficulty, also a few spoonfuls of milk. She said she swallowed easier if pressure were made on her chest front and back, but the difference was not obvious on experiment. She continued to complain of palpitation. The vesicles described by Marochetti were not present. There was no sense of constriction or of a band about the neck or chest. Morplia was administered subcutaneously.

October $2 \mathrm{~d}$ she was nuch worse. She had slept none. Had been very restless, sometimes getting up and walking the floor. Had sucked ice and taken a little lemon juice, otherwise nothing except the bromide. The frequent spasmodic respirations continued, and the intermediate respiration was faster. She appeared excited, gloomy, and anxious, but was rational. The face was much flushed. Pulse hard and irregular, abont 100. Action of the heart tumultuous. She was not dis- 
turbed by sight or sound of water, or by fanning. There had been thus far no convulsions nor real difficulty in swallowing a spoonful at a time. I ordered a mixture of bromide of potassium, chloral, and morphia, to be taken every hour till my return.

Towards noon, when about to take a dose of the medicine, she went into violent convulsions. When I arrived Drs. Page and Booth were already in attendance. She had been sitting with her feet in mustard water, with which she was rubbing her hands. She struggled somewhat, and required restraint. For a short time she had frequent clonic convulsions, some frothing at the mouth, and once or twice raised a little bloody fluid. Her face was livid, perspiration profuse, pupils large. She had an agitated, frightened look. She was quieted for a time by morphine subcutaneously. The previous peculiarities of respiration had disappeared. Fanning at this time disturbed her, though it did not cause convulsions. She was not affected by strong light. The clonic convulsive movements soon recurred at short intervals. If sitting on the bedside she would beat the floor rapidly with her feet, or the foot of the bed if lying down. Now and then she threw herself violently from side to side. Passed urine involuntarily. Heart very tumultuous, from 120 to 130 . The pupils reacted, though appearing somewhat dilated. She became very delirious after the first convulsions, with only momentary lucid intervals. She talked rapidly, wildly, profanely, and indecently; said she would harm no one; ate a lozenge with apparent relish. There were no tonic spasms, impeded respiration, flow of saliva, nor spitting.

Against my advice she was removed to the City Hospital, where she was in charge of Messrs. Leland and Sheldon. She continued raving, and as she did not remain in bed the camisole was applied. She threw up several times, without retching, large quantities of a brown, slimy fluid. There was considerable saliva about the mouth, and she swallowed frequently, as one talking rapidly. A dose of bromide, which she refused, was put into her mouth, and she swallowed two or three times when her chin was drawn down. The muscles of her neck became rigid, her face was blue, and there was well-marked laryngeal spasm. The spasm having remitted, she gasped two or three times, and died about three quarters of an hour after entrance. Her mouth filled immediately with foam, which protruded from between her lips.

Throughout the whole of October 1st, the first day of my attendance, there was nothing in her condition, considered apart from the history, to excite alarm. Hysteria would have explained it all, but the history made hydrophobia the probable diagnosis, and the condition the next day and the speedy death afforded ample confirmation.

Autopsy. The autopsy was made by Dr. F. W. Draper sixteen hours after death. Rigor mortis unusually marked. Fingers rigidly 
flexed, but not clenched. Face uniformly livid. Deep post-mortem staining (suggillation) over the entire posterior aspect of the body. Teeth closely joined. Frothy fluid escaped from the nostrils. Vessels of meninges of brain distinctly filled, but not distended with blood. Substance of brain apparently normal in its gross appearances. A drachm of clear fluid in each lateral ventricle.

Lungs healthy. Heart normal in size and in the firmness of its muscular wall. Right ventricle filled but not distended with mingled fluid and dark, clotted blood. Left ventricle contracted and nearly empty. Valves normal. The stomach contained about six ounces of a greenishbrown fluid of the consistency and nearly the color of pea soup. On the posterior wall at the cardiac end was a patch of finely disseminated points of ecchymosis about two inches in diameter. The spleen, kidneys, liver, and intestines presented nothing abnormal. The ovaries were small and shriveled in appearance. The uterus showed a small fibroid of the size of a filbert, projecting externally from the fundus. The lining membrane of the uterus was everywhere covered with a dirty-pinkish, semi-fluid material, which, being removed, left the mucous coat of normal appearance. The larynx showed nothing to indicate disease or mechanical obstruction within its cavity.

\section{HYDROPHOBIA.}

BY J. P. MAYNARD, M. D., DEDHAM.

THE apparently increasing frequency of this frightful and inevitably fatal disease ought to arouse the attention of the public to the urgent necessity of adopting such energetic means and effective measures as shall absolutely prevent all liability to its occurrence. It is hardly credible that at a public hearing, not long since, an individual could have shown such ignorance of medical science as to express a doubt of the existence of any such disease. In view of the possibility of such an absurd statement influencing the opinion of others who have no means of proper information, it becomes of the first importance that reliable statistics should be collected by all members of the profession reporting any authenticated cases that may fall under their observation.

For this purpose I will refer to the fact that the first case that came under my care was twenty years ago. The report was published at the time in the Boston Medical and Surgical Journal, October 15, 1857.

The second case, which I briefly condense, occurred in August, 1877. Mr. P. L., who had been bitten by a dog about six weeks previously, had been troubled for some two days with vague symptoms of distress: anorexia, lassitude, and lack of sleep, subsequently accompanied by difficulty of deglutition and slight spasmodic contractions of the throat. 